\title{
Teoria de van Hiele e investigação matemática: implicações para o ensino de Geometria
}

\section{Van Hiele theory and Mathematical Investigation: implications for teaching Geometry}

\author{
${ }^{1}$ Rita Maria Cargnin ritamariacargnin@yahoo.com.br \\ ${ }^{1}$ Sheila Heydt Réquia Guerra \\ 2 José Carlos Pinto Leivas
}

\section{RESUMO}

O presente artigo tem como finalidade relatar uma prática realizadacom alunos do $5^{\circ}$ ano do Ensino Fundamental de uma escola pública da zona Oeste da cidade de Santa Maria. Trata-se de uma pesquisa qualitativa que teve como objetivo investigar, por meio da Teoria de van Hiele, como os alunos identificam e classificam figuras geométricas, tendo como metodologiade ensino a Investigação Matemática. Esta pesquisa buscou aplicar os conhecimentos adquiridos na disciplina de Fundamentos de Geometria do Curso de Mestrado Profissionalizante em Ensino de Física e Matemática. Os resultados das atividades propostas e desenvolvidas de forma investigativa apontaram que os alunos alcançaram os primeiros níveis da teoria de van Hiele, o que possibilita uma avaliação positiva da proposta, considerando-se as particularidades do público-alvo da pesquisa, tais como maturidade intelectual e conhecimentos prévios.

Palavras-chave: Teoria de van Hiele. Investigação Matemática.Geometria.

\section{ABSTRACT}

This article aims to report a practice carried out with students from 5th grade of elementary school to a public school in the western part of the city of Santa Maria. This is a qualitative study that aimed to investigate, through the van Hiele theory, as students identify and classify geometric figures, with the methodology of teaching Mathematical Research. This research sought to apply the knowledge acquired in the discipline of Fundamentals of Geometry of the Professional Master's Course in Teaching Physics and Mathematics. The results of the activities proposed and developed of the form investigative showed that students achieved the first levels of the van Hiele theory, this enables a positive evaluation of the proposal, considering the particularities of the target audience research and intellectual maturity and prior knowledge.

Keywords: Theory of van Hiele. Mathematical Research.Geometry.

1 Mestranda do Curso de Mestrado Profissionalizante em Ensino de Física e de Matemática.

2 Professor do Curso de Mestrado Profissionalizante em Ensino de Física e de Matemática. 


\section{INTRODUÇÃO}

A Geometria é rica em elementos que favorecem o desenvolvimento do raciocínio visual e da percepção de espaço, fazendo-se presente em diversas áreas do conhecimento científico e na natureza de uma forma geral. De acordo com Pereira, Silva e Motta Jr. (2005, p.21), “a geometria é parte intrínseca do universo físico e também parte relevante da Matemática”.

Mesmo sem nos darmos conta, nos deparamos, diariamente, com objetos de diversas formas geométricas e com ideias de paralelismo, perpendicularismo, simetria, medição, entre outras. Sendo assim, o ensino de Geometria tem papel fundamental no desenvolvimento de habilidades e competências que servem de base para o entendimento e percepção desses fenômenos, para a aquisição e construção do conhecimento matemático e para o estabelecimento de conexões entre a Matemática e as outras áreas.

No entanto, autores como Lorenzato (1995), Pavanelo (1993), Leivas (2012), entre outros, ressaltam que a Geometria, nos diferentes níveis de ensino, tem apresentado problemas e dificuldades de aprendizagem e também de ensino. De maneira que, esseconteúdo não tem recebido a devida atenção e por vezes, torna-se ausente das salas de aula.

Lorenzato (1995) enumera duas causas principais para essa omissão. A primeira é que muitos professores não detêm os conhecimentos geométricos necessários para a realização de práticas pedagógicas, podendo ser um dos resultados da ausência ou da frágil presença da Geometria na grade curricular dos cursos de formação de professores da área da Matemática.

Corroborando com essa ideia de fragilidade, a pesquisa realizada por Leivas (2009) em oito Cursos de Licenciatura em Matemática do RS, verificou que, apesar de todos os cursos pesquisados ofertarem disciplinas de Geometria Plana e Geometria Espacial, essas, geralmente, são desenvolvidas de forma axiomática, com destaque para algoritmos e fórmulas, de forma a priorizar a Álgebra em relação à Geometria. Além disso, embora, haja uma possibilidade intrínseca de visualização em disciplinas que fazem uso de desenho geométrico, "não foi percebido qualquer indicativo de que imaginação, intuição e visualização sejam elementos norteadores do ensino de Geometria” (LEIVAS, 2012, p. 10).

A segunda causa da omissão, indicada por Lorenzato (1995), refere-se à demasiada importância dada ao livro didático. Em muitos casos, apresenta o conteúdo de Geometria carregado por definições, propriedades, teoremas, fórmulas, desvinculado de outros conteúdos como aritmética e álgebra e, de forma pouco contextualizada, privando os estudantes da visualização, análise e discussão de elementos e relações geométricas a partir de objetos do cotidiano. Além disso, na maioria das vezes, o conteúdo de Geometria é apresentado na última parte do livro, aumentando a probabilidade de não ser abordado devido à falta de tempo durante operíodo letivo.

Contudo, a relevância do ensino de Geometria e as competências a serem desenvolvidas com esse ensino, são reconhecidas por documentos educacionais oficiais, orientadores da escola básica nacional. Os Parâmetros Curriculares Nacionais (BRASIL, 1998) trazem considerações em relação à relevância e à necessidade de integração da Geometria desde os anos iniciais do Ensino Fundamental:

os conceitos geométricos constituem uma parte importante do currículo de Matemática no Ensino Fundamental, porque, por meio deles, o aluno desenvolve um tipo especial de pensamento que lhe permite compreender, descrever e representar, de forma organizada, o mundo em que vive (BRASIL, 1998, p. 51).

Diante deste cenário, é possível verificar a necessidadedevalorização e enriquecimento desse ensino nos diferentes níveis escolares. Isso pode ser alcançado por meio de atividades e metodologias diferenciadas, que 
instiguem a investigação e experimentação em sala de aula, tendo como suporte, além do livro didático, ferramentas tecnológicas, materiais concretos e manipuláveis, entre outros.Além disso, faz-se necessária, pelo professor, uma postura mais orientadora de ensino,de forma a valorizar a observação, a análise, a discussão, o estabelecimento de conjecturas e a generalização do conhecimento, por parte dos próprios alunos.

No intuito de favorecer a exploração e investigação de figuras geométricas planas e tornar esse estudo mais atrativo para alunos do $5^{\circ}$ ano do Ensino Fundamental, esta pesquisa utilizou-se da teoria de van Hiele e da metodologia de Investigação Matemática para analisar como os alunos classificam e conceituam diferentes figuras geométricas. Foram propostas atividadesinvestigativas adequadas ao público-alvo, para possibilitar a construção do conhecimento geométrico por parte dos próprios alunos e favorecer o avanço dos mesmos nos níveis de van Hiele.

\section{TEORIA DE VAN HIELE: IMPLICAÇÕES PARA O ENSINO DE GEOMETRIA}

O modelo de van Hieleconstitui-se em uma teoria de ensino e aprendizagem de Geometria, que teve origem nos anos 50, nas respectivas teses de doutorado de Dina Van Hiele-Geoldof e seu marido Pierre Van Hiele. O casal desenvolveu uma pesquisa com alunos de doze e treze anos, na Holanda, sob a orientação do educador matemático Hans Freudenthal, tendo como motivação as dificuldades enfrentadas, pelos estudantes, em sala de aula.

Enquanto a tese de Pierre tentava, principalmente, explicar e descrever o porquê os alunos tinham problemas ao aprender Geometria, a tese de Dina versava sobre um experimento educacional. O modelo desenvolvido pelo casal idealizava um novo enfoque para o desenvolvimento do raciocínio em Geometria, sugerindo níveis hierárquicos de compreensão e aprendizagem. Deste modo, "a principal característica da teoria é a distinção de cinco diferentes níveis de pensamentos com relação ao desenvolvimento da compreensão dos alunos acerca da Geometria” (VILLIERS, 2010, p. 400). Esses níveis são classificados de zero a quatro ou o equivalente, de um a cinco, e determinam as particularidades do processo do pensamento geométrico dos alunos, são eles: reconhecimento, análise, ordenação, dedução e rigor.

O estudo de Villiers (2010) concentra-se na caracterização dos quatro primeiros níveis. No nível, denominado básico ou de reconhecimento, os alunos reconhecem as figuras geométricas pela sua aparência física, ou seja, pela sua forma. No entanto, suas partes ou propriedades, geralmente, não são identificadas.Nesse nível, as figuras são analisadas apenas pelo visual e o vocabulário geométrico dos alunos é básico.Já no segundo nível, denominado análise, os alunos começam a perceber características das figuras e algumas propriedades, mas ainda não estabelecem relações entre elas.No terceiro nível, denominado ordenação, os alunos conseguem organizar e ordenar logicamente propriedades de figuras, por meio de curtas sequências de dedução e compreendem as correlações entre as figuras. No quarto nível começa-se a entender o papel dos axiomas, teoremas e provas e as condições necessárias e suficientes para definição e classificação das figuras, tendo como base o conhecimento adquirido nos níveis anteriores.

Já o último nível, denominado de rigor, é caracterizado, por Nasser (2000), como àquele em que o aluno é capaz de elaborar e compreender demonstrações e estabelecer comparações entre os diversos sistemas na Geometria, além de ser capaz de analisar e compreender geometrias não euclidianas. Essa teoria evidencia uma sequencialidade no progresso de um nível para outro e a dificuldade de compreensão de determinado conteúdo quando este é apresentado em um nível mais elevado que o atingido pelo aluno.

A teoria de van Hiele já é conhecida pelo público desde a década de 70. No Brasil teve como principal divulgadora a professora Lilian Nasser, do Projeto "Fundão" da Universidade Federal do Rio de Janeiro. 
De acordo com Nasser et al. (2000), cabe ao professor identificar o nível em que seus alunos se encontram e, a partir disso, desenvolver e proporcionar condições para que eles avancem. Isso inclui a proposição de atividades adequadas e o incentivo à participação dos alunos na construção do conhecimento, evoluindo se forma progressiva de um nível para outro.

\section{INVESTIGAÇÃO MATEMÁTICA}

Quando se fala em investigar pensa-se em buscar soluções, em encontrar alternativas para uma situação desconhecida. Segundo as ideias de Ponte et al. (2003), investigar matematicamente é descobrir relações entre objetos matemáticos conhecidos ou desconhecidos, procurando identificar as respectivas propriedades.

Tendo como base essa premissa, os autores afirmam que

em contextos de ensino e aprendizagem, investigar não significa necessariamente lidar com problemas muito sofisticados na fronteira do conhecimento. (...) Desse modo, investigar não representa obrigatoriamente trabalhar em problemas muito difíceis. Significa, pelo contrário, trabalhar com questões que nos interpelam e que se apresentam no início de modo confuso, mas que procuramos clarificar e estudar de modo organizado (PONTE et al., 2003, p. 9).

Na investigação matemática, o aluno vai atuar como um investigador à procura de soluções para uma situação apresentada pelo professor. Essas situações podem partir de exercícios simples ou situações-problema. Ponte et al. (2003) afirmam que as investigações matemáticas constituem uma das atividades que os alunos podem realizar e que se relacionam, muito de perto, com a resolução de problemas.

Para Ponte et al. (2003), a investigação matemática envolve quatro momentos principais: o primeiro momento é o reconhecimento da situação, onde se tem a exploração inicial, a leitura e a formulação de questões. É nesse momento que há a primeira leitura e o reconhecimento da situação apresentada, onde já se podem formular questões iniciais. O segundo momento refere-se ao processo de formulação de conjecturas. É a partir dessa fase, que o estudante começa a pensar no problema compreendido no primeiro momento, organiza os dados e formaliza as conjecturas. O terceiro momento inclui a realização de testes das conjecturas formuladas anteriormente e o possível refinamento das mesmas. O último momento refere-se à argumentação das possíveis soluções, socialização e demonstração do raciocínio utilizado. Neste último momento se faz uma avaliação do trabalho realizado.

Em relação ao ensino por meio de atividades investigativas, Ponte (2005) afirma que

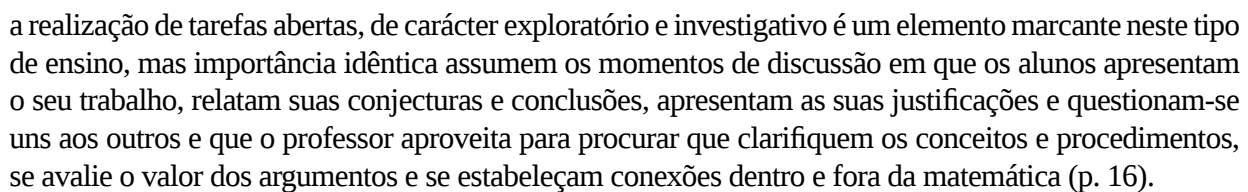

Por meio das características evidenciadas pelo autor, enfatiza-se a importância de propor atividades investigativas que possibilitem o envolvimento do aluno desde a primeira fase do processo, a formulação de questões a serem resolvidas, até os momentos de discussão, onde há oportunidade de construção do novo conhecimento de forma colaborativa.

Segundo Ponte (2010), as tarefas exploratórias e investigativas criam oportunidades para o envolvimento dos alunos nas aulas de matemática e isso interfere, fortemente, no trabalho do professor. A aprendizagem também depende de outros elementos que se relacionam juntamente com a prática do professor, que se referem aos demais participantes da investigação e aos fatores relacionados à comunicação entre os mesmos. 
Numa aula investigativa, as tarefas são importantes, mas a forma como essas tarefas são abordadas em sala de aula é o ponto fundamental de uma investigação. O professor tem papel fundamental numa aula de investigação. Em primeiro lugar, o professor necessita selecionar, adaptar ou até mesmo construir as tarefas que levem a desencadear uma investigação. Essas tarefas devem ser interessantes com vistas a despertar o interesse do aluno para uma investigação, levando em consideração a faixa etária dos alunos, os conhecimentos matemáticos já adquiridos e os seus interesses.

Na fase inicial de uma aula investigativa, o professor faz a proposta para a turma, entrega a tarefa por escrito aos alunos ou ao grupo e incentiva-os a serem exploradores, a buscarem uma ou mais soluções para tal desafio. Os alunos devem compreender o que irão realizar e entender o seu papel dentro da proposta investigativa. A partir da compreensão do que deve ser investigado, começa a fase onde o professor fica à disposição do aluno e acompanha o processo de formulação das hipóteses.

O professor, durante a fase investigativa, pode apoiar o aluno, recordando alguns conceitos já vistos, por meio de questionamentos que o levem a recordar a matemática já vista anteriormente. Os alunos devem ser encorajados a compartilharem as suas ideias com os demais colegas, com o objetivo de construir o conhecimento de forma colaborativa.

Após a investigação realizada, o professor segue a fase onde os resultados são compartilhados e os processos utilizados são socializados. Todos devem ser estimulados a participar e expor as suas ideias, dando sua opinião em relação aos argumentos e conclusões apresentadas.

Outro aspecto relevante a uma boa aula investigativa é o ambiente de aprendizagem. O professor precisa conhecer bem os seus alunos e, a partir daí, propor situações que venham ao encontro de suas expectativas, do seu cotidiano e não algo distante e sem interesse.

Sobre o papel do professor em uma atividade investigativa, Bisognin et al. (2009) ressaltam que

\begin{abstract}
a utilização dessa metodologia [investigação matemática] faz com que o professor desempenhe um papel de moderador das atividades. Ela exige do professor uma capacidade de reagir e interagir em situações improvisadas nas quais ele deixa de ter controle dos métodos e processos que os alunos utilizam, ou seja, não tem um caminho pré-determinado; em consequência, professor e alunos se transformam, interagindo entre si (p. 191).
\end{abstract}

Portanto, o professor que busca realizar atividades investigativas na sua prática profissional, precisa de algumas competências que vão muito além das utilizadas atualmente no cotidiano escolar. É necessário ter uma relação positiva com as investigações, estar disposto a enfrentar novas situações, propor tarefas investigativas que tenham sentido para o aluno, que façam parte do seu cotidiano e, acima de tudo, que proporcionem um ambiente propício a uma investigação. É possívelque, durante a atividade investigativa, os alunos formulem conjecturas que o professor não havia pensado. Cabe a esse professor tentar compreender tais conjecturas formuladas pelos alunos e, por meio do diálogo conjunto, explorar os conhecimentos buscando com que todos reflitam sobre as situações, privilegiando uma postura interrogativa com vistas a proporcionar o desenvolvimento do raciocínio matemático.

\title{
4 DESENVOLVIMENTO DA PESQUISA
}

Esta pesquisa classifica-se como qualitativa, de caráter exploratório, na qual as pesquisadoras participaram de todo o contexto em que ela foi realizada. Para coleta de dados foram utilizados os seguintes instrumentos: observação participante, diário de campo e análise dos registros dos alunos. 
A pesquisa foi aplicada no dia 13 de junho de 2014 com 14 alunos do $5^{\circ}$ ano do Ensino Fundamental de uma escola pública de Santa Maria/RS. A aplicação teve duração de 3 horas/aula.

A turmafoi dividida em grupos, para os quais foram propostas seisatividades que tiveram como objetivo a identificação, classificação e caracterização de figuras geométricas planas. Para o encaminhamento das atividades e exploração dos níveis de van Hiele, foi utilizada como suporte a metodologia de Investigação Matemática, seguindo-se as etapas propostas por Ponte et al. (2003): reconhecimento da situação, formulação de conjecturas, teste das conjecturas formuladas e argumentação das possíveis soluções.

Foi entregue cada atividade separadamente, obedecendo a uma sequencialidade de materiais, cuidadosamente preparados pelas pesquisadoras, e respeitando o ritmo dos alunos. Em cada atividade, disponibilizou-se tempo para que os alunos analisassem as figuras, discutissem em seus grupos e buscassem responder aos questionamentos. Em seguida, foi aberto um período para discussão, comparação e argumentação dos resultados, com todos os alunos da sala de aula. Para aprofundar a investigação foram realizadas intervenções, por parte das pesquisadoras, com questionamentos aos estudantes, estimulando-os a observarem, explorarem as figuras geométricas dispostas, estabelecerem conexões do conhecimento escolar com o cotidiano e, desta forma, construírem, gradualmente, seu conhecimento a cerca das mesmas.

\section{1 Atividade 1}

Nesta atividade foi entregue a cada um dos componentes dos grupos, uma fichacontendo um desenho,formado por diversas figuras geométricas, e alguns questionamentos que estimulavam a identificação e uma primeira classificação dessas figuras, uma vez que os alunos ainda não haviam trabalhado as características e o conceito a cerca de figuras geométricas planas, além de instigar a contextualização do desenho apresentado.

Haviaquatro fichas com desenhos diferentes, de forma que cada componente do grupo recebeu uma delas. Abaixo, é apresentada uma das fichas entregues aos alunos:

Figura 1 - Ficha da atividade 1

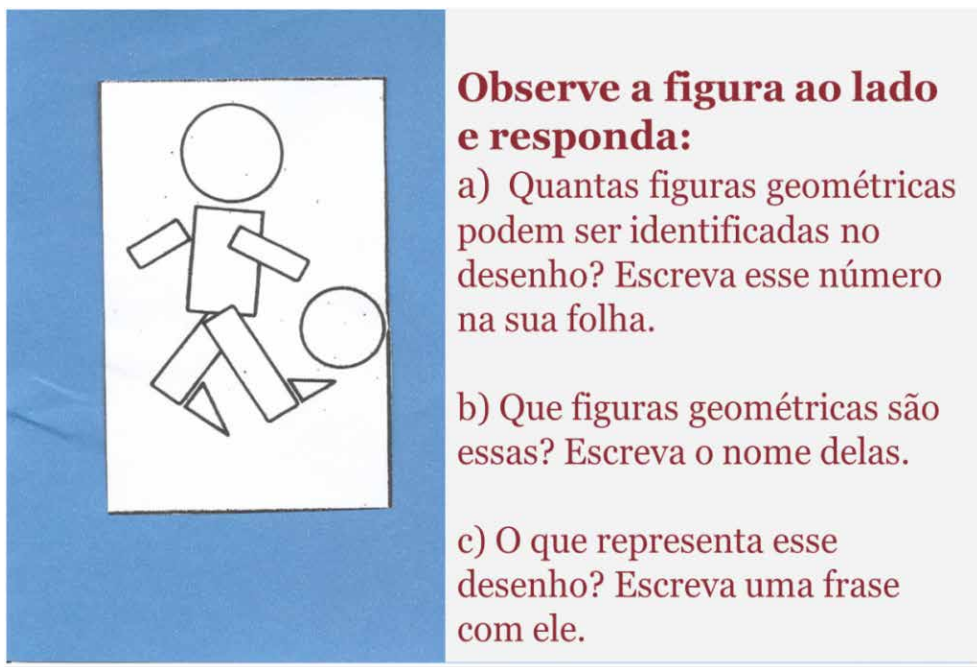

Fonte: própria

\subsubsection{Análise dos resultados da atividade 1}

No quadro 2 são apresentados alguns resultados a cerca desta primeira atividade. 


\section{Quadro 2 - Descrição das respostas dadas pelos alunos na atividade 1}

\begin{tabular}{|l|l|}
\hline Desenho & Descrição dos Resultados \\
\hline Passarinho & $\begin{array}{l}\text { Todos os alunos que possuíam este desenho identificaram } 7 \text { figuras, denominando-as por: triângulo, } \\
\text { círculo, quadrado, meio círculo. }\end{array}$ \\
\hline Foguete & Todos identificaram 9 figuras: triângulo, quadrado, retângulo, círculo, meio círculo e "bola”. \\
\hline Menino com bola & $\begin{array}{l}\text { Três alunos identificaram 9 figuras: triângulo, círculo e retângulo. } \\
\text { Um aluno identificou } 5 \text { figuras geométricas, denominando-as da mesma forma que os outros grupos. }\end{array}$ \\
\hline Menino com livro & $\begin{array}{l}\text { Todos os alunos identificaram 8 figuras. As mesmas foram denominadas de círculo, retângulo, } \\
\text { triângulo, "bola” e quadrado. }\end{array}$ \\
\hline
\end{tabular}

Fonte: própria

O termo "bola" foi utilizado, por alguns alunos, para denominar círculo. O que pode evidenciar um vocabulário geométrico ainda simples por parte deles, em que são utilizados termos conhecidos para a denominação de algumas figuras.

Analisando o desenvolvimento da atividade 1 foi possível constatar que os alunos identificaram as figuras pela sua aparência global, ou seja, pela sua forma, sem se deterem em características de componentes e suas propriedades, o que constata que satisfazem o primeiro nível da teoria de van Hiele.

\section{2 Atividade 2}

Para a atividade2 os grupos receberam uma folha com diversas figuras geométricas para que as recortassem e as classificassem de acordo com um critério livre, escolhido pelo grupo.Após, foi solicitado que cada grupo explicasse como havia realizado a classificação.

\subsubsection{Análise dos resultados da Atividade 2}

O quadro 3 apresenta a descrição dos resultados provenientes da atividade 2.

\section{Quadro 3 - Descrição da atividade 2}

\begin{tabular}{|l|l|l|}
\hline Grupos & Descrição dos Resultados & Considerações \\
\hline Grupo 1 & $\begin{array}{l}\text { Separou as figuras geométricas } \\
\text { pelas seguintes formas: } \\
\text { quadrados, retângulos, } \\
\text { triângulos e “figuras } \\
\text { esquisitas”. }\end{array}$ & $\begin{array}{l}\text { Neste caso os losangos foram classificados no grupo dos quadrados e os } \\
\text { paralelogramos no grupo dos retângulos. } \\
\text { As outras figuras (trapézios, pentágonos e hexágono) por sua vez, como não } \\
\text { se encaixavam em nenhuma das classificações anteriores, foram denominadas } \\
\text { por “figuras esquisitas”. }\end{array}$ \\
\hline Grupo 2 & $\begin{array}{l}\text { Separou pela quantidade de } \\
\text { pontas que as figuras tinham: } \\
\text { 3, 4, 5 e 6 pontas. }\end{array}$ & $\begin{array}{l}\text { As pontas, neste caso, se referiam aos vértices das figuras. Desta forma, } \\
\text { a classificação do grupo foi em figuras com 3 pontas (triângulos), 4 } \\
\text { pontas (quadriláteros), 5 pontas e 6 pontas. Essas duas últimas, não foram } \\
\text { denominadas pelo grupo. }\end{array}$ \\
\hline Grupo 3 & $\begin{array}{l}\text { Separou as figuras pelas suas } \\
\text { formas: triângulos, retângulos, } \\
\text { quadrados e "outras figuras”. }\end{array}$ & $\begin{array}{l}\text { Os losangos foram classificados como quadrados e os paralelogramos } \\
\text { como retângulos.As “outras figuras”, referem-se àquelas, as quais o grupo } \\
\text { desconhecia a denominação: trapézios, pentágonos e hexágonos. }\end{array}$ \\
\hline Grupo 4 & $\begin{array}{l}\text { Separoupela semelhança de } \\
\text { formas, denominando-as } \\
\text { por triângulos, quadrados e } \\
\text { retângulos. }\end{array}$ & $\begin{array}{l}\text { Novamente, os losangos foram classificados como quadrados e os } \\
\text { paralelogramos como retângulos. As figuras com } 5 \text { e 6 lados foram } \\
\text { separadas, utilizando-se como critério o número de lados, mas não receberam } \\
\text { denominações específicas. }\end{array}$ \\
\hline
\end{tabular}


Pode-se observar que os grupos não realizaram somente a classificação das figuras pelo número de lados: triângulos, quadriláteros, pentágonos e hexágonos. Eles se utilizaram da aparência global das figuras, como por exemplo, no caso dos quadriláteros, a separação se deu em retângulos e quadrados. Por desconhecerem as características (ângulos, lados paralelos...) e as definições de losango, paralelogramo e trapézio, essas figuras foram englobadas nos demais grupos. As figuras de 5 e 6 lados, também não receberam denominações específicas, elas foram classificadas pelo número de lados que possuíam.

Desta forma, pode-se observar, nesta atividade, que os alunos ainda se encontravam no nível um da Teoria de van Hiele, nível básico ou de reconhecimento, onde as figuras são classificadas visualmente, ou seja, apenas pela sua aparência, não sendo consideradas as características e os elementos que as compões, nem suas propriedades.

Com vistas a contextualizar as atividades realizadas em sala de aula e tornar o aprendizado mais estimulante e conectado com a realidade, foram utilizados objetos do cotidiano dos alunos, para queos mesmos pudessem identificar figuras geométricas envolvidas. Entre os objetos explorados, estava a bandeira do Brasil, que possibilitou aos alunos identificarem semelhanças e diferenças entre figuras, as quais geraram dúvidas durante a classificação, como entre quadrados e losangos, entre retângulos e quadrados e entre retângulos e paralelogramos.

\section{3 Atividade 3}

Nesta atividade solicitou-se que os alunos tomassem somente as figuras com três lados, a fim de explorá-las mais detalhadamente, deixando as demais figuras reservadas para as demais atividades.

Buscando a caracterização e classificação dessas figuras, foram realizados questionamentos, como: quantas figuras de 3 lados vocês possuem? Todas as figuras são iguais? É possível separá-las em outros grupos?

\subsubsection{Análise dos resultados da atividade 3}

No primeiro momento, os alunos tiveram dificuldades em achar um critério para separação dos triângulos em outros grupos. Buscando auxiliá-los nesta classificação e estimulá-los a observar também os componentes dos triângulos, as pesquisadoras interagiram com os grupos com questionamentos, como: "quantos vértices essas figuras possuem?”; “quantos ângulos?”; “como são os seus lados?” Neste momento foram explicitadas rapidamente noções de ângulos e vértices, com auxílio de materiais concretos e exemplos do cotidiano, uma vez que os alunos não possuíamo conhecimentodesses conceitos, devido ao projeto político pedagógico para esse nível escolar.

Como os alunos observaram que todas as figuras possuíam o mesmo número de vértices e ângulos, foram instigados a buscar outro critério de classificação. Foi solicitado que observassem, por exemplo, o tamanho de cada figura. Então, com auxílio da régua,os alunos mediram os lados dos triângulos e anotaram as medidas dos mesmos. Eles observaram que as medidas dos lados dos triângulos eram variadas. Ao analisar cada triângulo, separadamente, perceberam que alguns possuíam todos os lados com a mesma medida, em outros todas as medidas eram diferentes e, em alguns, havia apenas dois lados com a mesma medida.

Após essas observações, foram entregues fichas com a classificação e denominação dos triângulos, quanto à medida dos lados, para que fizessem a colagem das respectivas figuras e escrevessem suas características, conforme demonstra a figura 2. 
Figura 2 - Ficha da atividade 3 do grupo 1

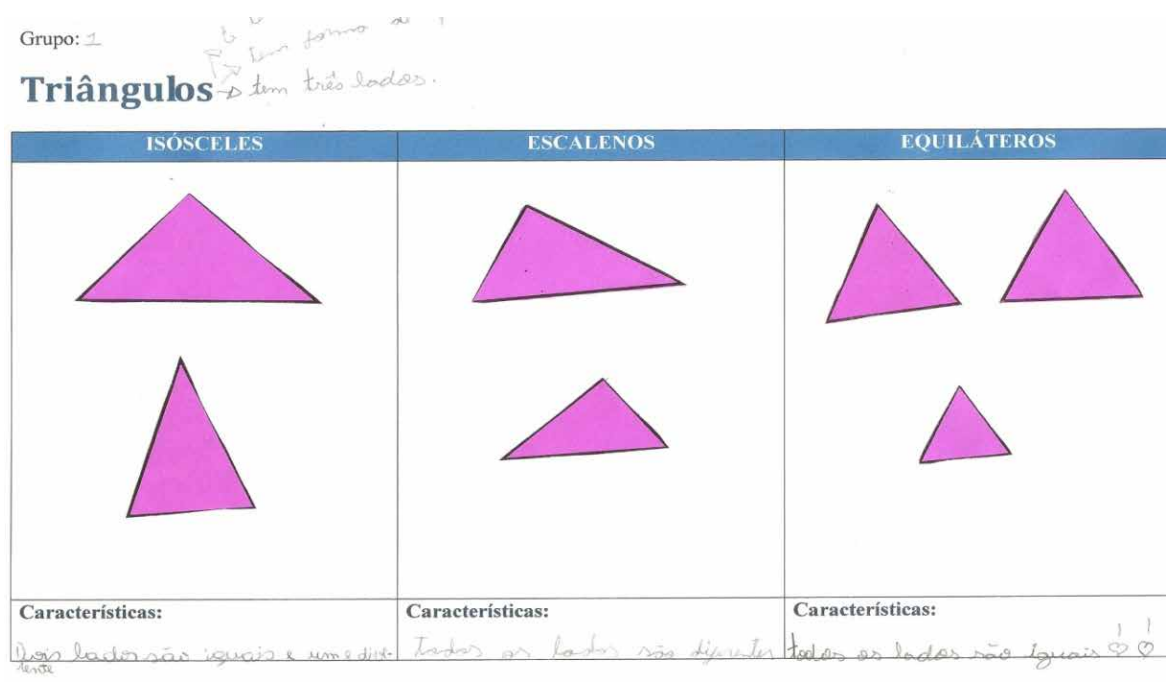

Fonte: própria

\section{4 Atividade 4 e descrição dos resultados}

Após a exploração dos triângulos na atividade 3, foi solicitado aos grupos que tomassem as figuras de quatro lados e as classificassem de acordo com algum critério.

Intuitivamente, a maioria dos alunos classificou as figuras em quadrados e retângulos. Eles incluíram, novamente, os losangos junto com os quadrados e os paralelogramos, com os retângulos. Os trapézios foram deixados em grupo à parte.

De forma semelhante à realizada na atividade 3, após os grupos exporem sua classificação, foram direcionados alguns questionamentos, pelas pesquisadoras,a fim de que os alunos justificassem suas classificações: “tomando a figura do losango, porque você a classificou como um quadrado?”; “o paralelogramo pode ser um retângulo? Por quê?”, “o quadrado não pode ser um retângulo? "Por que você classificou algumas figuras como esquisitas? O que elas têm de diferente das demais?”

Buscando auxiliar os alunos na compreensão das semelhanças e diferenças entre os quadriláteros exploramos visualmente no quadro as noções de ângulos, com exemplos do cotidiano, citados por eles: rampa de um prédio, parede da sala de aula, escada. Além disso, foram utilizados transferidores para mostrar como se medem os ângulos. Utilizando exemplos do dia a dia, tais como as ruas do bairro, foi explicado sobre lados paralelos e perpendiculares.

Após essa explanação pedimos que os grupos observassem novamente a sua classificação. Os alunos foram percebendo as diferenças existentes nas figuras nas quais possuíam dúvidas. Em relação ao quadrado e losango, perceberam que os dois possuem todos os lados com a mesma medida, mas diferem quanto aos ângulos, pois somente o quadrado possui todos os ângulos retos. De forma semelhante ocorreu com o retângulo e o paralelogramo, perceberam que os dois possuem os lados opostos com a mesma medida, mas que somente o retângulo possui todos os ângulos retos, ou seja, de $90^{\circ}$.

Para finalizar a atividade, foi entregue uma nova ficha para que os grupos colassem as figuras de acordo com a classificação: quadrados, retângulos, losangos, paralelogramos, trapézios. Elesdeveriam escrever as respectivas características, conforme ilustrado na figura 3: 
Figura 3 - Ficha da atividade 4 completada pelo grupo 1

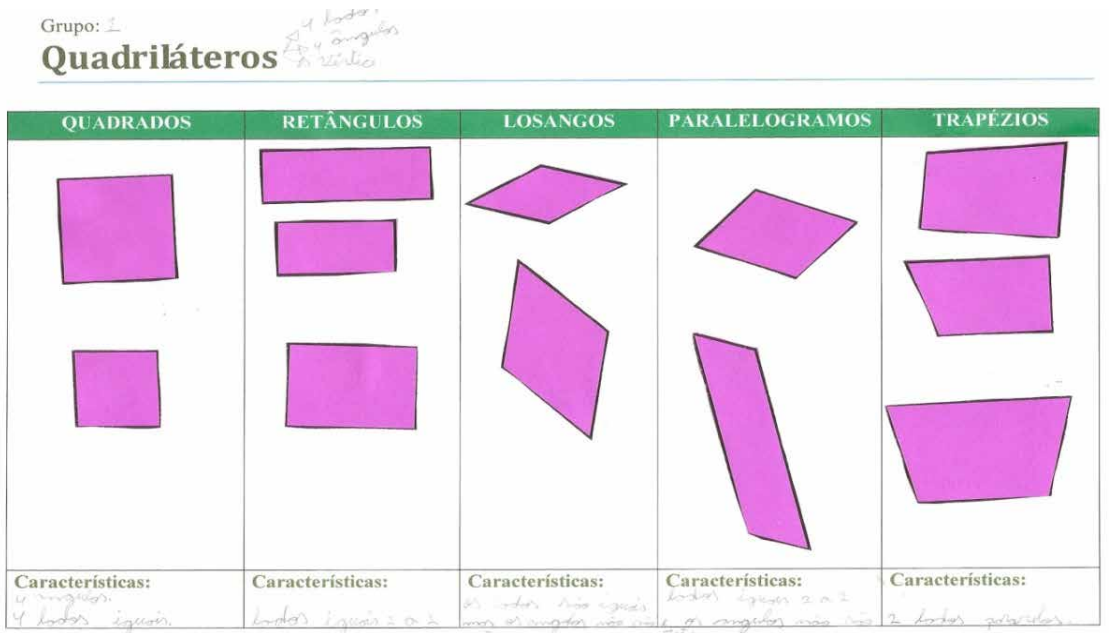

Fonte: própria

\section{5 Atividade 5 e descrição dos resultados}

Nesta atividade foi solicitado que os grupos separassem as figuras de 5 e 6 lados e observassem suas características, como lados, vértices, ângulos e figuras com as quais essas são formadas.

Os alunos não tinham conhecimento da denominação dessas figuras, então foi sendo explorada sua nomenclatura, utilizando-se dos últimos títulos do Brasil no futebol mundial: pentacampeão e hexacampeão. Além disso, foi levadaà sala de aula,uma bola de futebol e solicitado que observassem os"gomos” que compunham essa bola, ou seja, para perceberem a composição desta bola como um conjunto de pentágonos e hexágonos interligados, podendo esses serem decompostos em figuras já exploradas nas atividades anteriores: triângulos, trapézios, retângulos.

De forma semelhante às atividades anteriores, os alunos organizaram suas fichas, classificando e caracterizando os pentágonos e hexágonos, conforme ilustrado na figura 4.

Figura 4 - Ficha da atividade 5 completada pelo grupo 2

Grupo: 2

Pentágonos e Hexágonos

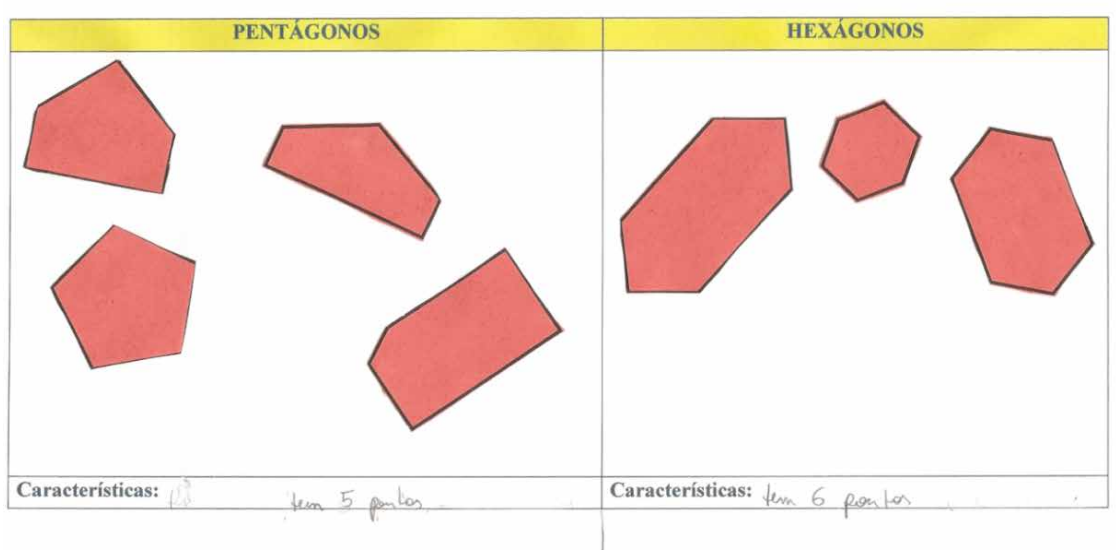

Fonte: própria 


\section{6 Atividade complementar}

Após o encerramento das atividades anteriores, foi entregue aos alunos uma folha com diversas figuras geométricas,já estudadas no decorrer das atividades anteriores. Foi solicitado que as recortassem e realizassem sua classificação utilizando como critério seus componentes e características: ângulos, lados congruentes, lados paralelos, entre outras. Em seguida, solicitou-se aos alunos que montassem desenhos, do seu cotidiano, obtidos com essas figuras.

A seguir são apresentados alguns desses desenhos elaborados pelos grupos:

Figura 5 e 6 - Desenhos elaborados pelos alunos

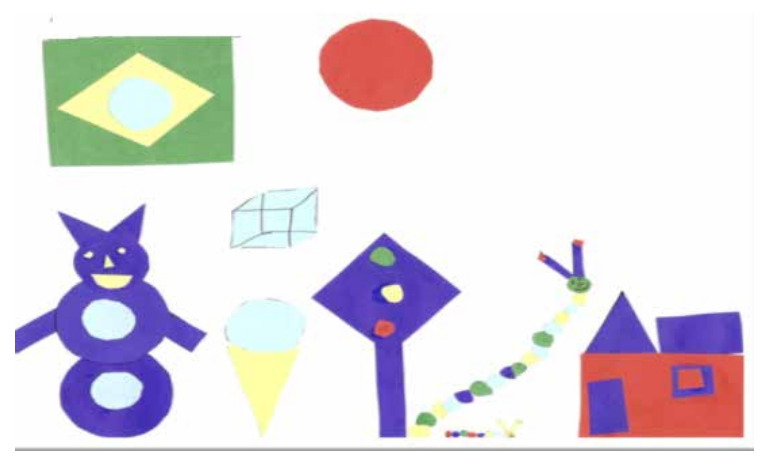

Fonte: aluno

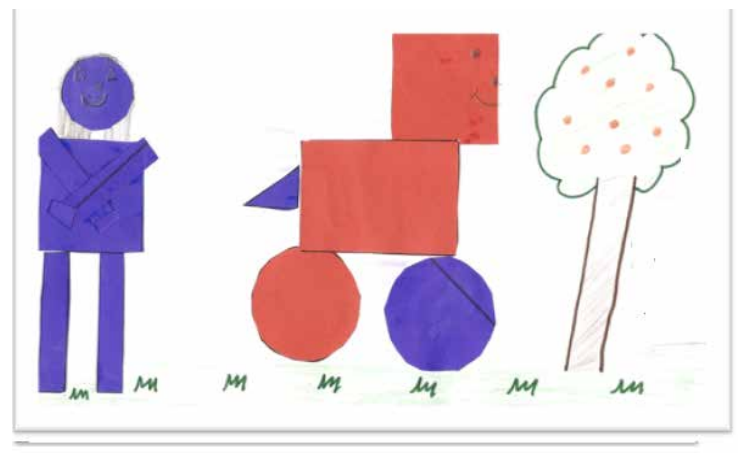

Fonte: aluno

\section{CONSIDERAÇÕES FINAIS}

No desenvolvimento da pesquisa percebemos que houve um grande interesse por parte dos alunos na realização das atividades. Os grupos mantiveram-se entusiasmados e conseguiram desenvolver as atividades de forma satisfatória, respondendo, muitas vezes, além da expectativa das pesquisadoras.

Um ponto a ser destacado foi aaproximação da Geometria à realidade dos alunos, como meio de esclarecimento de dúvidas e explanação de conceitos que eles não conheciam, como ângulos retos e oblíquos, ideias de paralelismo, perpendicularismo, dentre outros.

Na atividade l, considerada o ponto de partida para essa investigação, os alunos compreenderam bem a tarefa e sentiram-se motivados à exploração das figuras, uma vez que envolviam desenhos lúdicos, os quais propiciavam diversas interpretações. Isso, comprovaas afirmações de Ponte et al. (2003), de que é imprescindível observar se os alunos compreenderam bem a tarefa na fase denominada de arranque da investigação, considerada fundamental para o desenvolvimento da atividade investigativa. O professor, a partir dessa fase, continua sendo um incentivador, de maneira que a atividade avance normalmente. Os autores afirmam também que as tarefas devem ser interessantes com vistas a despertar o interesse do aluno, levando em consideração a faixa etária, os conhecimentos matemáticos já adquiridos e os seus interesses.

No decorrer das atividades pode-se evidenciar um progresso dos alunos nos níveis de desenvolvimento do raciocínio geométrico de van Hiele. De modo que, nas duas primeiras atividades, os alunos identificaram e classificaram as figuras de acordo com sua aparência global, classificando-as de maneira intuitiva, sem apropriação conceitual e reconhecimento de propriedades envolvidas, o que corresponde ao primeiro nível da teoria de van Hiele, denominado de nível básico ou de reconhecimento.No entanto, a partir da atividade 3, foi possível 
observar que os alunos adquiriram certa autonomia no desenvolvimento das atividades, bem como na identificação e análise das figuras, não somente emsua totalidade, como também em relação aos seus componentes e às possíveis associações entre esses. Pode-se observar, desta forma, que no decorrer da proposta houveprogresso do raciocínio geométrico dos alunos.

Pode-se concluir queas atividades propostas nesta pesquisa utilizaram a ludicidade dos desenhos para motivar os alunos. Os questionamentos realizados pelas pesquisadoras impulsionaram os alunos a observarem e analisarem as figuras geométricas em suas particularidades e possibilitaram conexões do conhecimento escolar com o cotidiano.

Desta forma, o conhecimento acerca dos níveis da teoria de van Hiele, associado àmetodologia da Investigação Matemática, possibilitou a construção do conhecimentoe o avanço nos níveis de raciocínio geométrico dos alunos, desde a classificação intuitiva das figuras geométricas, o que corresponde ao nível um, até a análise mais aprofundada das mesmas, o que equivale ao segundo nível desta teoria.

Em virtude dasatividades investigativas terem sido aplicadas a alunos dos primeiros anos do Ensino Fundamental, considera-se que o nível de desenvolvimento do raciocínio geométrico atingido por elesfoi satisfatório, uma vez que o avanço em cada nível depende da maturidade intelectual do aluno, dos seus conhecimentos prévios e do seu avanço nos níveis anteriores. 


\section{REFERÊNCIAS}

BISOGNIN, E.; BISOGNIN, V.; BURIOL, C.; Atividades de investigação como alternativa metodológica para o ensino de matemática. In: FROTA, M. C. R.; NASSER, L. (Org.). Educação Matemática no Ensino Superior: Pesquisa e debates. Recife: SBEM, 2009. p. 189-202.

BRASIL. Ministério da Educação. Secretaria de Educação Fundamental. Parâmetros Curriculares Nacionais: Matemática. Brasília, 1998.

LEIVAS, J. C. P. Imaginação, Intuição e Visualização: a riqueza de possibilidades da abordagem geométrica no currículo de cursos de licenciatura de matemática. 2009. Tese (Doutorado em Educação) - Universidade Federal do Paraná. Curitiba, 2009, 294 p.

. Educação geométrica: reflexões sobre o ensino e aprendizagem em geometria. Educação Matemática em Revista/RS. v. 1, n. 13, p. 9-16, 2012.

LORENZATO, S. Por que não ensinar geometria? Educação Matemática em Revista. SBEM. n. 4, Campinas, 1995.

NASSER, L, et al. Geometria segundo a teoria de van Hiele. 3 ed. Instituto de Matemática/UFRJ: Projeto Fundão, 2000.

PAVANELO, R. M. O abandono de ensino de geometria no Brasil: causas e consequencias. Revista Zeteliké. n.1, ano 1, Unicamp, 1993.

PEREIRA, G. A.; SILVA, S. P.; MOTTA Jr.; W. S. O modelo de van Hiele de Ensino de Geometria aplicado à $5^{\text {a e }}$ $6^{a}$ séries do Ensino Fundamental. FAMAT em Revista, n. 5, p. 21-50, setembro de 2005. Disponível em: <http:// www.pet.famat.ufu.br/sites/pet.famat.ufu.br/files/ArtigoGislianeSandreaneWalter>. Acesso em: 04 jul. 2014.

PONTE, J. P. Gestão curricular em Matemática. In: GTI (Ed.). O professor e o desenvolvimento curricular. Lisboa: APM, 2005. p. 11-34. Disponível em: < http://www.educ.fc.ul.pt/docentes/jponte/docs-pt/05-Ponte GTI-tarefas-gestao.pdf $>$. Acesso em: 3 abr. 2014.

Explorar e investigar em matemática: Uma actividade no ensino e na aprendizagem. UNIÓN: Revista Iberoamericana de Educación Matemática, n. 21, p. 13- 30, marzo, 2010.

PONTE, J. P., BROCARDO, J., OLIVEIRA, H. Investigações Matemáticas na Sala de Aula. Belo Horizonte: Autêntica, 2003. 152 p.

VILLIERS, M. de.Some reflections on the Van Hiele Theory.Tradução: Celina A. A. P. Abar. Educação Matemática Pesquisa, São Paulo, v.12, n. 3, p. 400-431, 2010. Disponível em: <revistas.pucsp.br/index.php/ article/view/5167>. Acesso em: 09 mar. 2014. 